\title{
Cardiac multi-marker strategy for effective diagnosis of acute myocardial infarction
}

Citation for published version (APA):

Xu, Q., Chan, C. P. Y., Cao, X., Peng, P., Mahemuti, M., Sun, Q., Cheung, K., Ip, W., Zhou, X., Hu, G., Zhang, X., Jielile, J., Li, Y., Ren, R., GlatZ, J. F. C., \& Renneberg, R. (2010). Cardiac multi-marker strategy for effective diagnosis of acute myocardial infarction. Clinica Chimica Acta, 411(21-22), 17811787. https://doi.org/10.1016/j.cca.2010.07.033

Document status and date:

Published: 11/11/2010

DOI:

10.1016/j.cca.2010.07.033

Document Version:

Publisher's PDF, also known as Version of record

Document license:

Taverne

Please check the document version of this publication:

- A submitted manuscript is the version of the article upon submission and before peer-review. There can be important differences between the submitted version and the official published version of record.

People interested in the research are advised to contact the author for the final version of the publication, or visit the DOI to the publisher's website.

- The final author version and the galley proof are versions of the publication after peer review.

- The final published version features the final layout of the paper including the volume, issue and page numbers.

Link to publication

\footnotetext{
General rights rights.

- You may freely distribute the URL identifying the publication in the public portal. please follow below link for the End User Agreement:

www.umlib.nl/taverne-license

Take down policy

If you believe that this document breaches copyright please contact us at:

repository@maastrichtuniversity.nl

providing details and we will investigate your claim.
}

Copyright and moral rights for the publications made accessible in the public portal are retained by the authors and/or other copyright owners and it is a condition of accessing publications that users recognise and abide by the legal requirements associated with these

- Users may download and print one copy of any publication from the public portal for the purpose of private study or research.

- You may not further distribute the material or use it for any profit-making activity or commercial gain

If the publication is distributed under the terms of Article $25 \mathrm{fa}$ of the Dutch Copyright Act, indicated by the "Taverne" license above, 


\title{
Cardiac multi-marker strategy for effective diagnosis of acute myocardial infarction
}

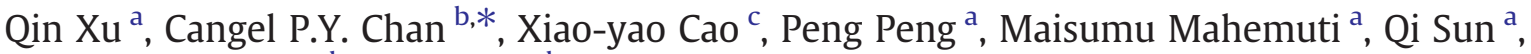 \\ Kwan-yee Cheung ${ }^{d}$, Wai-sze Ip ${ }^{\mathrm{b}}$, Xin-rong Zhou ${ }^{\mathrm{a}}$, Ge-yang $\mathrm{Hu}^{\mathrm{a}}$, Xiao-feng Zhang ${ }^{\mathrm{e}}$, Jiasharete Jielile ${ }^{\mathrm{a}}$, \\ Yao-dong Li ${ }^{a}$, Rong Ren ${ }^{f}$, Jan F.C. Glatz ${ }^{\mathrm{g}}$, Reinhard Renneberg ${ }^{\mathrm{b}, *}$ \\ a The First Affiliated Hospital of Xinjiang Medical University, Urumqi, China \\ ${ }^{\mathrm{b}}$ Department of Chemistry, The Hong Kong University of Science and Technology, Hong Kong \\ c Intensive Care Unit, The Xinjiang Urumqi Friendship Hospital, China \\ d REC Biogenius Limited, Hong Kong \\ e The First People's Hospital of Xinjiang Aksu Region, China \\ ${ }^{\mathrm{f}}$ The Fifth Affiliated Hospital of Xinjiang Medical University, China \\ ${ }^{g}$ Department of Molecular Genetics, Cardiovascular Research Institute Maastricht, Maastricht University, The Netherlands
}

\section{A R T I C L E I N F O}

\section{Article history:}

Received 8 February 2010

Received in revised form 12 June 2010

Accepted 26 July 2010

Available online 4 August 2010

\section{Keywords:}

Acute myocardial infarction (AMI)

Cardiac troponin I (cTnI)

Creatine kinase MB (CK-MB)

Heart-type fatty acid-binding protein (H-FABP)

Multi-marker

\begin{abstract}
A B S T R A C T
Background: Heart-type fatty acid-binding protein (H-FABP) is a heart-specific and highly sensitive biomarker for early diagnosis of acute myocardial infarction (AMI). We investigated the effectiveness of H-FABP for diagnosis of AMI in patients with different ethnic background and different time from symptom onset.

Methods: Venous blood was withdrawn from consecutive patients with acute chest pain admitted to the First Affiliated Hospital of Xinjiang Medical University. The blood samples were used for measurement of creatine kinase MB (CK-MB) and cardiac troponin I (cTnI) using Beckman Coulter DC-800 analyzer, and detection of H-FABP using a one-step bedside immunotest.

Results: Two hundred and eighty-nine patients admitted within $12 \mathrm{~h}$ after the onset of symptoms were recruited in the study. The H-FABP immunotest was found to have higher diagnostic accuracy than cTnI and CK-MB in patients admitted within $3 \mathrm{~h}$. The combination of H-FABP and cTnI was found to have the highest diagnostic accuracy (91\%) among different cardiac markers and the other combinations. It gave the highest sensitivity [96\% (95\% CI: 91-98\%)] and a comparable specificity [84\% (95\% CI: 76-89\%)] to cTnI alone. Conclusion: A cardiac panel consisting of H-FABP and troponin is recommended.
\end{abstract}

(c) 2010 Elsevier B.V. All rights reserved.

\section{Introduction}

Cardiovascular disease causes a major burden in health care and is the single most costly disease for the health care system. It has been increasing in the past few decades in China, the largest and most populous developing country in the world. Acute myocardial infarction (AMI) is the leading cause of mortality among cardiovascular disease. The high mortality rate can be dramatically reduced by early diagnosis and effective coronary reperfusion.

From the ED perspective, it is important to expeditiously distinguish between AMI and non-AMI patients so as to be able to immediately start

Abbreviations: ACC, American College of Cardiology; AMI, acute myocardial infarction; cTnI, cardiac troponin I; ESC, European Society of Cardiology; H-FABP, heart-type fatty acid-binding protein; IQR, interquartile ranges; LR-, negative likelihood ratio; LR+, positive likelihood ratio; MYO, myoglobin; NPV, negative predictive value; PPV, positive predictive value; WHO, World Health Organization.

* Corresponding authors. Department of Chemistry, The Hong Kong University of Science and Technology, Clear Water Bay, Kowloon, Hong Kong. Renneberg is to be contacted at Tel.: + 8522358 7387; fax: + 8522358 1594. Chan, Tel.: + 8522358 0220; fax: + 85223581594 .

E-mail addresses: cangel@ust.hk (C.P.Y. Chan), chrenneb@ust.hk (R. Renneberg). proper treatment. Although electrocardiogram (ECG) is a standard test to identify patients with AMI upon ED presentation, it still has relatively low sensitivity for detection of AMI (only 35-50\%) [1]. Instead, plasma markers of myocardial injury ultimately show almost 100\% sensitivity, dependent on the delay in their release into plasma.

Recently, a one-step bedside H-FABP immunotest so-called CardioDetect ${ }^{\circledR}$ designed to detect H-FABP in whole blood samples has become commercially available [2-6]. The test result is available within 15 min after addition of blood samples. It requires no sample pretreatment and, therefore, is suitable especially for application in an emergency situation. Many studies in the developed countries like Europe and Japan have demonstrated the superior performance of H-FABP for diagnosis of AMI in the early stage [7-12]. However, such information is still relatively insufficient in the developing countries with inconvenient traffic, low educational level, lack of hospital resources and comprehensive facilities. Study about the utility of H-FABP for diagnosis of AMI in China is also limited.

The prevalence of several chronic diseases in Xinjiang including myocardial infarction, diabetes, hypertension, and cancers is difference among different ethnic groups. Therefore, the present study aimed at investigating the effectiveness of the H-FABP immunotest compared to 
current cardiac markers for diagnosis of AMI in patients with different ethnic background, different chronic diseases, different genders and different time from symptom onset in Xinjiang. Also, the diagnostic performance of different combinations of cardiac markers was compared. This study may act as a reference for those developing countries and the results can be compared to those studies conducted in developed countries to assess the universal applicability of the H-FABP immunotest for diagnosis of AMI. This study has been divided into two phases: Phase I has been implementing in Urumqi for $3 \mathrm{y}$; Phase II will be implemented in the southern, northern and eastern parts of Xinjiang for $4 \mathrm{y}$.

\section{Methods}

\subsection{Study design and setting}

According to the Declaration of Helsinki, the design of this study was to investigate the diagnostic accuracy of the H-FABP immunotest. This study was reviewed and approved by the ethical committee of the First Affiliated Hospital of Xinjiang Medical University in November 2007 with document number: No. 20071108. The First Affiliated Hospital of Xinjiang Medical University is a teaching hospital in the western border of area of Urumqi in Xinjiang. In 2007, there were 2332 visits for cardiovascular diseases to the Emergency Department (ED) of this hospital; 502 of them suffered from chest pain and 158 of these patients ultimately have been diagnosed as acute myocardial infarction (AMI) and 57 as angina pectoris.

This was a double-blind parallel study. Consecutive patients with acute chest pain admitted to the ED of the First Affiliated Hospital of Xinjiang Medical University were diagnosed according to the ESC/ACC guideline and the H-FABP immunotest. Fig. 1 showed the diagnostic pathway in this study.

A comprehensive study design and accurate data collection were relied on a well-organized preliminary study. The preliminary study was implemented from September 2007 to November 2007 and 40 consecutive patients were recruited. The study protocol were revised and finalized after the preliminary study. All the patients in the preliminary study were not included in the current study.

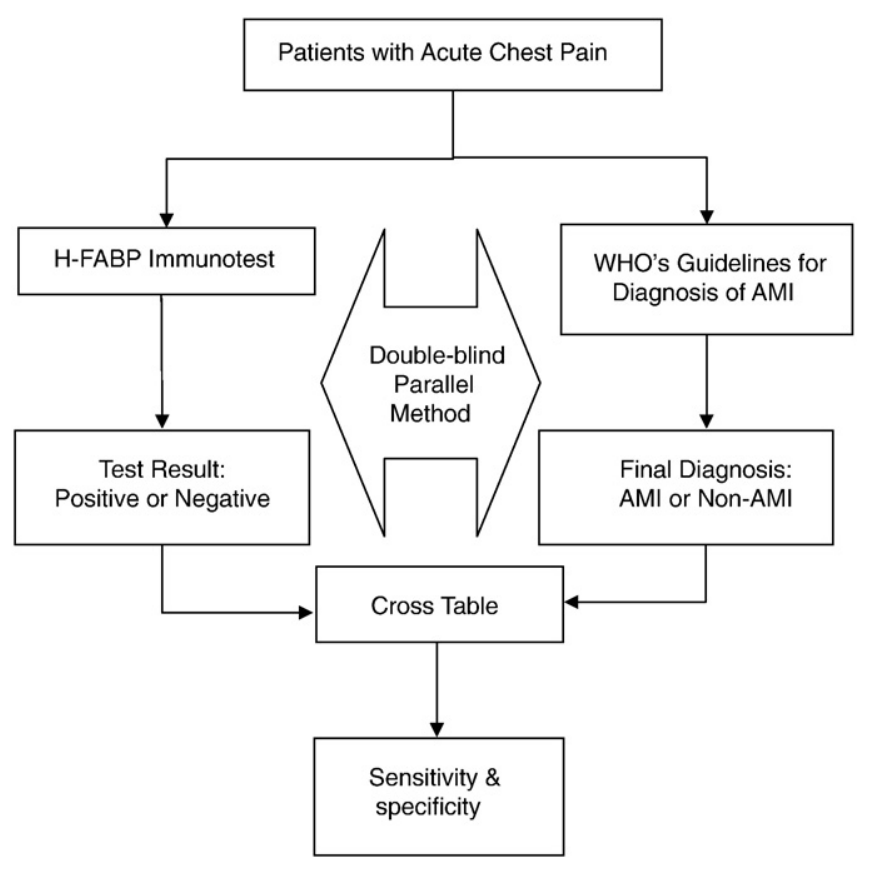

Fig. 1. Diagnostic pathway of the study.

\subsection{Inclusion and exclusion criteria}

Patients were included in this study if (i) they aged $\geq 18 \mathrm{y}$, (ii) chest pain suggestive of coronary origin at the discretion of an ED physician's assessment, (iii) and onset of chest pain $<12 \mathrm{~h}$ prior to enrollment. Patients were excluded if (i) they were unable to give consent or unwilling to join the study; (ii) they had chronic renal injury (creatinine in serum $>100 \mathrm{~mol} / \mathrm{l}$ or $>1.5 \mathrm{mg} / \mathrm{dl}$ ); (iii) they had intention neuralgia or recent pain related to thoracic trauma within 3 days; (iv) they had severe skeletal muscle injury.

\subsection{Patient assessments and investigations}

According to the ESC/ACC guideline [13,14], patients were confirmed as AMI patients if they had (i) typical acute chest pain; (ii) abnormal 12-lead ECG defined as pathologic Q waves of $>40 \mathrm{~ms}$, ST-segment elevation or depression of $>1 \mathrm{~mm}$ or abnormal $\mathrm{T}$ wave morphology; (iii) the cTnI concentration above the 99th percentile cutoff with a $\mathrm{CV}<10 \%$.

The onset time of symptoms was critical in this study. The time was based on the subjective reports of the patients about the onset of chest pain. In order to minimize the variation, the medical doctors asked the patients and their relatives twice respectively. The ECG was examined by 2 internal medicine specialists and the final result was reported by the Vice Director at the ED.

\subsection{Laboratory analysis}

Venous blood was withdrawn from patients suspected of AMI at admission. The blood samples were used for detection of CK-MB, cTnI and H-FABP. The concentrations of CK-MB and cTnI were determined by using Beckman Coulter DC-800 chemistry analyzer. The cut-off values for $\mathrm{CK}-\mathrm{MB}$ and $\mathrm{CTnI}$ were set at $25 \mathrm{U} / \mathrm{l}$ and $0.03 \mu \mathrm{g} / \mathrm{l}$ respectively. The final report was approved by a senior medical doctor in the Department of Laboratory Medicine. The measurement of all the cardiac markers using the analyzer in each sample was completed within 30-50 min. The final diagnosis was made by the Director at CCU and the Director at ED who were blinded to the H-FABP results.

All patients were also tested with CardioDetect ${ }^{\circledR} \mathrm{H}$-FABP immunotest (Fig. 2). It is a rapid chromatographic immunoassay designed for

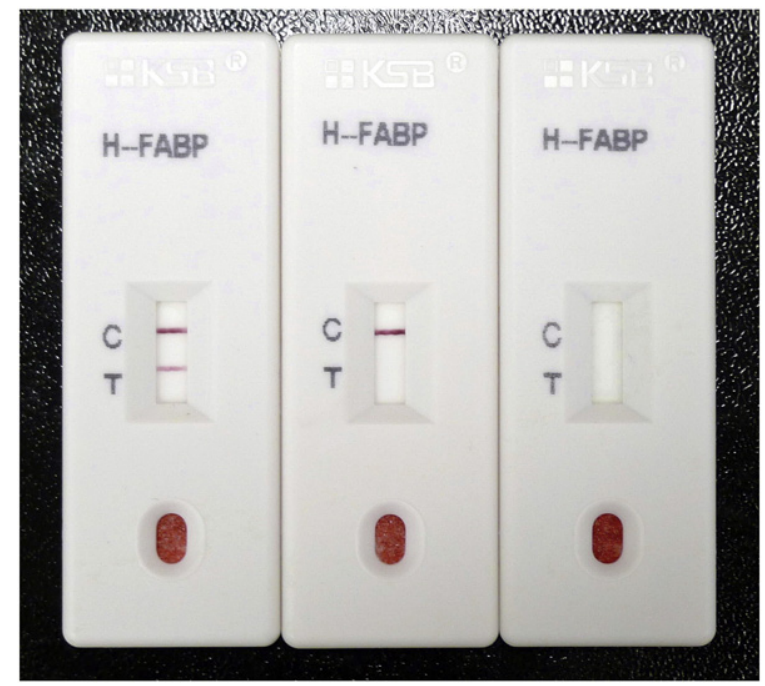

Fig. 2. CardioDetect ${ }^{\circledR}$ : a chromatographic immunotest for qualitative detection of H-FABP. The test result was positive if two red lines were visible (left). The result was negative if only one red line was visible at the control zone (middle). The test was invalid if no control line was visible (right). 
qualitative determination of H-FABP in blood samples with a cut-off value of $7 \mu \mathrm{g} / \mathrm{l}$. The working principle of the H-FABP immunotest was based on a sandwich immunoassay using a pair of monoclonal antibodies with the detector labeled with colloidal gold. The test required $100-120 \mu \mathrm{l}$ of sample and the result was interpreted within 15 min after sample application. The test result was positive if two red lines were visible (one at the area of the test zone and one at the control zone). This indicated that the concentration of H-FABP in the sample was above the threshold value of $7 \mu \mathrm{g} / \mathrm{l}$ and that an AMI had occurred. The result was negative if only 1 red line was visible at the control zone. This reading indicated that the concentration of H-FABP in the sample was below the threshold value and that an AMI had not occurred. The test was invalid if no line was visible or if a line only at the test zone was visible. In such a case, the measurement was repeated immediately.

The result of the H-FABP immunotest was judged by two independent master students at CCU. They had no information about the final diagnosis. The results and the final diagnosis were summarized in a cross table for analysis by a doctoral student who did not participate in any measurement. The study database was setup and organized by two statisticians by using double data entry and double checking method to ensure data accuracy.

\subsection{Clinical trial registration}

The World Health Organization (WHO) officially announced the expansion of its clinical trial registry platform to include trial registers from China in July 2007. This study was registered under the Chinese Clinical Trial Register (http://www.ctrni.org) in November 2007. The clinical trial registration number was ChiCTR-DT-00000040.

\subsection{Statistical analysis}

Data are presented as medians and interquartile ranges (IQR). Sensitivities with $95 \%$ confidence intervals (95\% CI), specificities with 95\% CI, negative and positive predictive values (NPV and PPV), negative and positive likelihood ratios (LR- and LR + ) of each cardiac marker and different combinations in 2 groups with different onset of symptoms (0-6 vs. 6-12 h) and in different ethnic groups were calculated by using SPSS13.0 (Chicago, IL) and MedCalc ver 7.0 (MedCalc Software, Mariakerke, Belgium). Diagnostic accuracy was defined as a proportion of correctly classified subjects (TP $+\mathrm{TN}$ ) among all subjects $(\mathrm{TP}+\mathrm{TN}+\mathrm{FP}+\mathrm{FN})$. The level of significance was set at $p<0.05$ (Table 1 ).

Table 1

Demographic characteristics and risk factors of study subjects.

\begin{tabular}{lccc}
\hline & $\mathrm{n}$ & AMI & Non-AMI \\
\hline Age, year [M(P25, P75)] & $61(50,69)$ & $61(50,70)$ & $60(46,69)$ \\
$\quad$ Sex (\%) & 274 & $157(57)$ & 117 \\
$\quad$ Male & 196 & $121(62 \%)$ & 75 \\
$\quad$ Female & 78 & $36(46 \%)$ & 42 \\
& & & \\
Ethnic group (\%) & 180 & $98(54 \%)$ & 82 \\
Han & 66 & $43(65 \%)$ & 23 \\
Uygur & 17 & $9(53 \%)$ & 8 \\
Hui & 9 & $5(56 \%)$ & 4 \\
Kazakh & 2 & $2(100 \%)$ & 0 \\
Xibe & & & \\
& & & \\
Risk factors (\%) & 63 & $30(48 \%)$ & 33 \\
Diabetes & 133 & $51(38 \%)$ & 82 \\
Hypertension & 109 & $37(34 \%)$ & 72 \\
History of ischemic heart disease & 165 & $91(55 \%)$ & 74 \\
History of smoking & 26 & $12(46 \%)$ & 14 \\
History of cerebrovascular disease & 26 &
\end{tabular}

\section{Results}

Between 19 November 2007 and 15 February 2009, 289 patients were recruited to the study (Fig. 3). Three patients without consent and 12 patients' diagnosis not based on the ESC/ACC guideline were excluded. Therefore, 15 patients were excluded leaving 274 patients (median age: $61 \mathrm{y}$; IQR: $50-70 \mathrm{y}$; $28.5 \%$ female) for analysis. Among the 274 patients, there were 180 Han patients (65.8\%), 66 Uygur patients (24\%), 17 Hui patients (6.2\%), 9 Kazak patients (3.3\%) and 2 Xibo patients $(0.7 \%)$. The median time from symptom onset to the first blood sample was $5 \mathrm{~h}$ (IQR: 3-6 h).

\subsection{Diagnostic performance of H-FABP immunotest}

The diagnostic performance of different cardiac markers and the combinations in patients suspected of AMI admitted to the hospital within $12 \mathrm{~h}$ after the onset of symptoms is summarized in Table 2. The sensitivity and specificity of the H-FABP immunotest were $87 \%$ (95\% CI: 81-92\%) and 84\% (95\% CI: 76-89\%) respectively. The PPV and NPV were $88 \%$ and $83 \%$ respectively. The LR+ and LRwere 5.37 and 0.15 respectively. The false negative ratio was $13 \%$ while the false positive ratio was $16 \%$. There were 19 patients with false positive results including 4 patients with cerebrovascular accident, 4 unstable angina patients, 3 patients with old myocardial infarction, 2 patients with cardiac arrhythmia, 2 patients with essential hypertension (grade III), 1 patient with pulmonary embolism, 1 patient with acute pancreatitis, 1 patient with left ventricular failure and 1 patient with stable angina.

The H-FABP immunotest was found to have higher sensitivity and NPV than CK-MB while its specificity and PPV were comparable to both $\mathrm{CTnI}$ and CK-MB. At the time of ED presentation, the use of both early and late markers rather than the gold standard troponins alone increases the diagnostic performance. The combination of H-FABP and cTnI was found to have the best diagnostic performance among different cardiac markers and the other combinations. It gave the highest sensitivity and NPV while its specificity and PPV were comparable to cTnI alone (Table 2).

\subsection{Diagnostic performance of different cardiac markers in patients with different time from symptom onset}

The sensitivity and specificity of H-FABP were 79\% (95\% CI: 65\%-89\%) and $80 \%$ (95\% CI: 65\%-89\%) respectively for patients admitted $0-3 \mathrm{~h}$ after the onset of symptoms, while the sensitivity and specificity of H-FABP increased to $93 \%$ (95\% CI: $83 \%-97 \%$ ) and 90\% (95\% CI: $77 \%-96 \%$ ) respectively for patients admitted $6-12 \mathrm{~h}$ after the onset of symptoms (Table 2).

Among patients admitted $0-3 \mathrm{~h}$ after the onset, the H-FABP immunotest was found to have higher sensitivity and specificity than both $\mathrm{CTnI}$ and CK-MB. The combination of H-FABP and CTnI was found to have the highest diagnostic accuracy (85\%) among different cardiac markers and the other combinations in the early phase of AMI.

Among patients admitted 6-12 h after the onset, both the sensitivities and specificities of all single cardiac markers increased to $90 \%$ or above while only the sensitivity of CK-MB was slightly below $90 \%$. The diagnostic performance of cTnI and the combination of cTnI and CK-MB was the best among different cardiac markers and the other combinations in the late phase of AMI.

Among patients admitted $0-12 \mathrm{~h}$ after the onset, the combination of H-FABP and cTnI was found to have the highest diagnostic accuracy (91\%) among different cardiac markers and the other combinations. It gave the highest sensitivity [96\% (95\% CI: 91-98\%)] and a comparable specificity [84\% (95\% CI: 76-89\%)] to cTnI alone. 


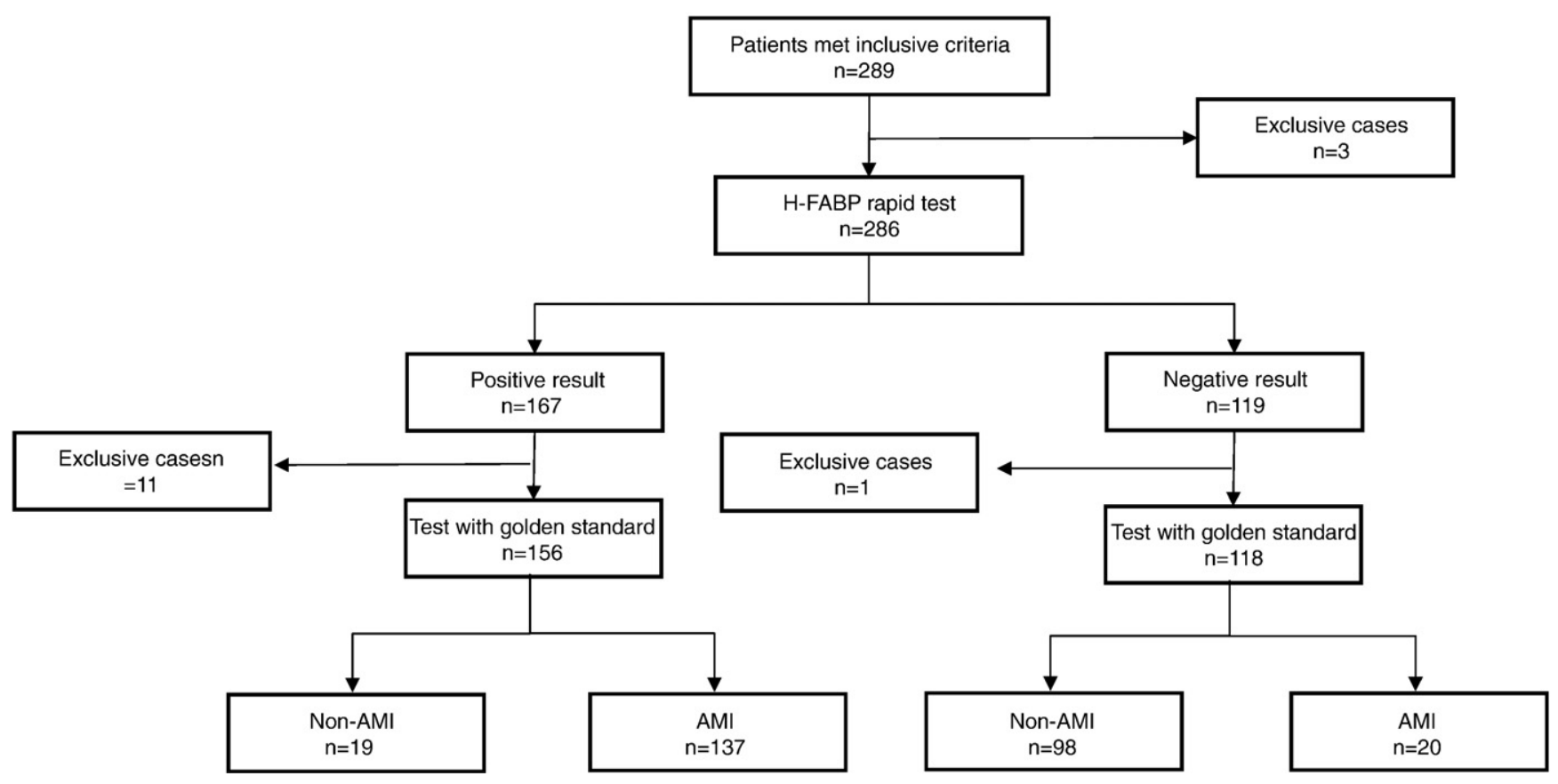

Fig. 3. Flow chat of study population.

3.3. Diagnostic performance of H-FABP immunotest in different ethnic groups

The sensitivity and specificity of H-FABP in the Han patients were $87 \%$ (95\% CI: 81\%-92\%) and 85\% (95\% CI: 76\%-91\%), while the sensitivity and specificity of H-FABP in the Uygur patients were 88\% (95\% CI: 76\%-95\%) and 78\% (95\% CI: 58\%-90\%) (Table 3). There was no statistically significant difference in the diagnostic perfor- mance of the H-FABP immunotest among the Han and Uygur patients $(p>0.05)$.

\subsection{Diagnostic performance of H-FABP immunotest in patients of different genders}

The sensitivity and specificity of H-FABP in males were 90\% (95\% CI: 83\%-94\%) and 86\% (95\% CI: 77\%-92\%) respectively, while the sensitivity

Table 2

Diagnostic performance of H-FABP immunotest, cTnI and CK-MB for diagnosis of AMI.

\begin{tabular}{|c|c|c|c|c|c|c|c|c|c|c|c|c|c|}
\hline Onset time & & $\mathrm{n}$ & TP & FP & FN & $\mathrm{TN}$ & $\begin{array}{l}\text { Diagnostic } \\
\text { accuracy }\end{array}$ & Sen $95 \% C I$ & Spe $95 \%$ CI & $\mathrm{LR}+$ & LR- & $\mathrm{PV}+$ & PV- \\
\hline \multirow[t]{7}{*}{$0-3 \mathrm{~h}$} & H-FABP & 87 & 34 & 9 & 9 & 35 & 0.79 & $0.79(0.65-0.89)$ & $0.80(0.65-0.89)$ & 3.87 & 0.26 & 0.79 & 0.80 \\
\hline & cTnI & 87 & 33 & 10 & 10 & 34 & 0.77 & $0.77(0.62-0.87)$ & $0.77(0.63-0.87)$ & 3.38 & 0.3 & 0.77 & 0.77 \\
\hline & CK-MB & 87 & 27 & 10 & 16 & 34 & 0.70 & $0.63(0.48-0.76)$ & $0.77(0.63-0.87)$ & 2.76 & 0.48 & 0.73 & 0.68 \\
\hline & $\mathrm{H}-\mathrm{FABP}+\mathrm{cTnI}$ & 87 & 40 & 10 & 3 & 34 & 0.85 & $0.93(0.81-0.98)$ & $0.77(0.63-0.87)$ & 4.09 & 0.09 & 0.80 & 0.92 \\
\hline & H-FABP + CK-MB & 87 & 35 & 13 & 8 & 31 & 0.76 & $0.81(0.67-0.90)$ & $0.70(0.56-0.82)$ & 2.75 & 0.26 & 0.74 & 0.79 \\
\hline & cTnI + CK-MB & 87 & 34 & 14 & 9 & 30 & 0.74 & $0.79(0.65-0.89)$ & $0.68(0.53-0.80)$ & 2.49 & 0.31 & 0.71 & 0.77 \\
\hline & $\mathrm{H}-\mathrm{FABP}+\mathrm{cTnI}+\mathrm{CK}-\mathrm{MB}$ & 87 & 40 & 14 & 3 & 30 & 0.80 & $0.93(0.81-0.98)$ & $0.68(0.53-0.80)$ & 2.92 & 0.10 & 0.74 & 0.91 \\
\hline \multirow[t]{7}{*}{$3-6 h$} & H-FABP & 92 & 52 & 6 & 7 & 27 & 0.86 & $0.88(0.77-0.94)$ & $0.82(0.66-0.91)$ & 4.85 & 0.15 & 0.90 & 0.79 \\
\hline & cTnI & 92 & 55 & 2 & 4 & 31 & 0.93 & $0.93(0.84-0.97)$ & $0.94(0.80-0.98)$ & 15.38 & 0.07 & 0.96 & 0.89 \\
\hline & CK-MB & 92 & 34 & 2 & 25 & 31 & 0.71 & $0.58(0.45-0.69)$ & $0.94(0.80-0.98)$ & 9.51 & 0.45 & 0.94 & 0.55 \\
\hline & $\mathrm{H}-\mathrm{FABP}+\mathrm{cTnI}$ & 92 & 58 & 5 & 1 & 28 & 0.93 & $0.98(0.91-1.00)$ & $0.85(0.69-0.93)$ & 6.49 & 0.02 & 0.92 & 0.97 \\
\hline & H-FABP + CK-MB & 92 & 51 & 5 & 8 & 28 & 0.86 & $0.86(0.75-0.93)$ & $0.85(0.69-0.93)$ & 5.71 & 0.16 & 0.91 & 0.78 \\
\hline & cTnI + CK-MB & 92 & 54 & 4 & 5 & 29 & 0.90 & $0.92(0.82-0.96)$ & $0.88(0.73-0.95)$ & 7.55 & 0.10 & 0.93 & 0.85 \\
\hline & $\mathrm{H}-\mathrm{FABP}+\mathrm{cTnI}+\mathrm{CK}-\mathrm{MB}$ & 92 & 58 & 4 & 1 & 29 & 0.95 & $0.98(0.91-1.00)$ & $0.88(0.73-0.95)$ & 8.11 & 0.02 & 0.94 & 0.97 \\
\hline \multirow[t]{7}{*}{$6-12 \mathrm{~h}$} & $\mathrm{H}-\mathrm{FABP}$ & 95 & 51 & 4 & 4 & 36 & 0.92 & $0.93(0.83-0.97)$ & $0.90(0.77-0.96)$ & 9.27 & 0.08 & 0.93 & 0.90 \\
\hline & cTnI & 95 & 52 & 1 & 3 & 39 & 0.96 & $0.95(0.85-0.98)$ & $0.98(0.87-1.00)$ & 37.82 & 0.06 & 0.98 & 0.93 \\
\hline & CK-MB & 95 & 49 & 3 & 6 & 37 & 0.91 & $0.89(0.78-0.95)$ & $0.93(0.80-0.97)$ & 11.88 & 0.12 & 0.94 & 0.86 \\
\hline & $\mathrm{H}-\mathrm{FABP}+\mathrm{cTnI}$ & 95 & 52 & 4 & 3 & 36 & 0.93 & $0.95(0.85-0.98)$ & $0.90(0.77-0.96)$ & 9.45 & 0.06 & 0.93 & 0.92 \\
\hline & $\mathrm{H}-\mathrm{FABP}+\mathrm{CK}-\mathrm{MB}$ & 95 & 51 & 7 & 4 & 33 & 0.88 & $0.93(0.83-0.97)$ & $0.83(0.68-0.91)$ & 5.30 & 0.09 & 0.88 & 0.89 \\
\hline & $\mathrm{cTnI}+\mathrm{CK}-\mathrm{MB}$ & 95 & 52 & 1 & 3 & 39 & 0.96 & $0.95(0.85-0.98)$ & $0.98(0.87-1.00)$ & 37.82 & 0.06 & 0.98 & 0.93 \\
\hline & $\mathrm{H}-\mathrm{FABP}+\mathrm{cTnI}+\mathrm{CK}-\mathrm{MB}$ & 95 & 52 & 7 & 3 & 33 & 0.89 & $0.95(0.85-0.98)$ & $0.83(0.68-0.91)$ & 5.40 & 0.07 & 0.88 & 0.92 \\
\hline \multirow[t]{7}{*}{ Overall } & $\mathrm{H}-\mathrm{FABP}$ & 274 & 137 & 19 & 20 & 98 & 0.86 & $0.87(0.81-0.92)$ & $0.84(0.76-0.89)$ & 5.37 & 0.15 & 0.88 & 0.83 \\
\hline & cTnI & 274 & 140 & 13 & 17 & 104 & 0.89 & $0.89(0.83-0.93)$ & $0.89(0.82-0.93)$ & 8.03 & 0.12 & 0.92 & 0.86 \\
\hline & CK-MB & 274 & 110 & 15 & 47 & 102 & 0.77 & $0.70(0.62-0.77)$ & $0.87(0.80-0.92)$ & 5.46 & 0.34 & 0.88 & 0.68 \\
\hline & $\mathrm{H}-\mathrm{FABP}+\mathrm{cTnI}$ & 274 & 150 & 19 & 7 & 98 & 0.91 & $0.96(0.91-0.98)$ & $0.84(0.76-0.89)$ & 5.88 & 0.05 & 0.89 & 0.93 \\
\hline & H-FABP + CK-MB & 274 & 137 & 25 & 20 & 92 & 0.84 & $0.87(0.81-0.92)$ & $0.79(0.70-0.85)$ & 4.08 & 0.16 & 0.85 & 0.82 \\
\hline & cTnI + CK-MB & 274 & 140 & 22 & 17 & 95 & 0.86 & $0.89(0.83-0.93)$ & $0.81(0.73-0.87)$ & 4.74 & 0.13 & 0.86 & 0.85 \\
\hline & $\mathrm{H}-\mathrm{FABP}+\mathrm{cTnI}+\mathrm{CK}-\mathrm{MB}$ & 274 & 150 & 25 & 7 & 92 & 0.88 & $0.96(0.91-0.98)$ & $0.79(0.70-0.85)$ & 4.47 & 0.06 & 0.86 & 0.93 \\
\hline
\end{tabular}

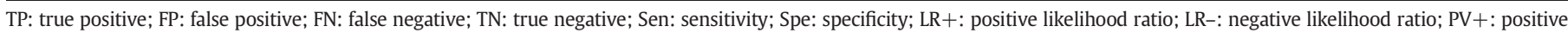
predictive value: PV-: negative predictive value. 
Table 3

Diagnostic performance of H-FABP immunotest in patients with different ethnics, genders and chronic diseases.

\begin{tabular}{|c|c|c|c|c|c|c|c|c|c|c|c|c|}
\hline & $\mathrm{n}$ & $\mathrm{TP}$ & FP & FN & $\mathrm{TN}$ & $\begin{array}{l}\text { Diagnostic } \\
\text { accuracy }\end{array}$ & Sen $(95 \% C I$ & Spe $(95 \% \mathrm{CI})$ & $\mathrm{LR}+$ & LR- & $\mathrm{PV}+$ & PV- \\
\hline \multicolumn{13}{|l|}{ Ethnic group } \\
\hline Han & 180 & 85 & 12 & 13 & 70 & 0.86 & $0.87(0.79-0.92)$ & $0.85(0.76-0.91)$ & 5.80 & 0.15 & 0.88 & 0.84 \\
\hline Uygur & 66 & 38 & 5 & 5 & 18 & 0.85 & $0.88(0.76-0.95)$ & $0.78(0.58-0.90)$ & 4.00 & 0.15 & 0.88 & 0.78 \\
\hline Hui & 17 & 8 & 1 & 1 & 7 & - & - & - & - & - & - & - \\
\hline Kazakh & 9 & 5 & 1 & 0 & 3 & - & - & - & - & - & - & - \\
\hline Xibe & 2 & 1 & 0 & 1 & 0 & - & - & - & - & - & - & - \\
\hline \multicolumn{13}{|l|}{ Gender } \\
\hline Male & 196 & 105 & 11 & 12 & 68 & 0.88 & $0.90(0.83-0.94)$ & $0.86(0.77-0.92)$ & 6.54 & 0.12 & 0.91 & 0.85 \\
\hline Female & 78 & 32 & 8 & 8 & 30 & 0.79 & $0.80(0.65-0.90)$ & $0.79(0.64-0.89)$ & 3.80 & 0.25 & 0.80 & 0.79 \\
\hline \multicolumn{13}{|l|}{ Chronic disease } \\
\hline Diabetes and hypertension & 19 & 11 & 3 & 2 & 3 & 0.74 & $0.85(0.58-0.96)$ & $0.50(0.19-0.81)$ & 9.13 & 0.17 & 0.79 & 0.60 \\
\hline Diabetes only & 63 & 28 & 6 & 6 & 23 & 0.81 & $0.82(0.66-0.92)$ & $0.79(0.62-0.90)$ & 3.98 & 0.22 & 0.82 & 0.79 \\
\hline Hypertension only & 133 & 47 & 7 & 9 & 70 & 0.88 & $0.84(0.72-0.91)$ & $0.91(0.82-0.96)$ & 9.23 & 0.18 & 0.87 & 0.89 \\
\hline No diabetes and hypertension & 59 & 51 & 3 & 3 & 2 & 0.90 & $0.94(0.85-0.98)$ & $0.40(0.12-0.77)$ & 1.57 & 0.14 & 0.94 & 0.40 \\
\hline
\end{tabular}

Note: as the number of cases of Hui, Kazakh and Xibe groups were small, the diagnostic accuracy, Sen, Spe, PV+, PV-, LR+, LR- were not calculated.

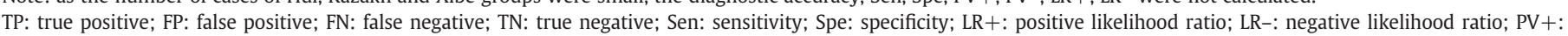
positive predictive value: $\mathrm{PV}-$ : negative predictive value.

and specificity of H-FABP in females were $80 \%$ (95\% CI: 65\%-90\%) and $79 \%$ (95\% CI: 64\%-92\%) respectively (Table 3 ). There was no statistically significant difference in the diagnostic performance of the H-FABP immunotest among males and females $(p>0.05)$. The diagnostic performance of H-FABP was higher in males than in females.

\subsection{Diagnostic performance of H-FABP immunotest in patients with different chronic diseases}

The diagnostic performances of H-FABP in patients with and without diabetes and hypertension were shown in Table 3. Patients without both diabetes and hypertension gave the highest sensitivity [94\% (95\% CI: 85\%-98\%)] but the lowest specificity [40\% (95\% CI: 12\%77\%)]. Patients with only hypertension gave the optimal sensitivity [84\% (95\% CI: 72\%-91\%)] and specificity [91\% (95\% CI: 82\%-96\%)].

\section{Discussion}

\subsection{Diagnostic performance of H-FABP immunotest}

The appropriate handling of patients with suspected AMI depends on the availability of results from simple, sensitive and specific diagnostic tests. In patients with typical early ECG changes of STsegment elevation, the diagnosis of AMI is easily and rapidly established. However, at least $40 \%$ of patients with AMI show no diagnostic ECG changes on admission. Also, in approximately 60 to $70 \%$ of patients admitted to hospital because of chest pain, the suspicion of AMI will ultimately be dismissed because of lack of diagnostic ECG changes and negative biochemical tests. In the past, early diagnosis of AMI mainly depended on the detection of myocardial injury markers such as cardiac troponins, creatine kinase (CK) or its isoenzyme (CK-MB), and myoglobin (MYO). Heart-type fatty acid binding protein (H-FABP) has been suggested as an early cardiac marker for diagnosis of AMI [15-21]. It is a small cytosolic protein and is abundant in cardiac tissue. It is responsible for the intracellular transport of the insoluble fatty acids within the cells. Its concentration in the plasma of healthy persons is relatively low at $0.3-6 \mu \mathrm{g} / 1[15,22]$. After myocardial ischemic damage, $\mathrm{H}$-FABP can be detected in the blood as early as within $1 \mathrm{~h}$ after onset of chest pain, with peak values reached at 3-6 h and plasma levels returning to normal within $24-30 \mathrm{~h}[16,22]$. The combination of initial H-FABP release after symptom onset, rapid kidney clearance from the circulation and high cardiac specificity makes it as an early cardiac marker for diagnosis of AMI and reinfarction.
This study has demonstrated that the H-FABP immunotest gave higher sensitivity and specificity than CTnI and CK-MB in patients admitted to the hospital within $3 \mathrm{~h}$ after the onset of symptoms. The small molecular weight of H-FABP ( $15 \mathrm{kDa}$ ) favors its early release, due to the higher permeability of the endothelial barrier for small proteins. Also, the amount of H-FABP in myocardium is 10 -fold higher than that in skeletal muscle. These characteristics, along with a low physiological concentration for the identification of myocardial damage, enable H-FABP to have an improved diagnostic capability $[23,24]$. The use of the H-FABP immunotest appears to be of unique value in the early stage of AMI. Chan et al. demonstrated that H-FABP reliably diagnosed AMI patients $1 \mathrm{~h}$ after admission and $100 \%$ of nonAMI patients were excluded with no false negative results [16]. The late markers cTnI and creatine kinase (CK) have the similar diagnostic performance only $7 \mathrm{~h}$ later.

Most of previous studies have reported that H-FABP gave significantly higher sensitivity and better diagnostic performance than cTnI especially at the early phase of AMI $[5,6,12,25,26]$. In this study, we found that the sensitivities of H-FABP and cTnI were comparable. This may be explained by the utilization of different cutoff values for $\mathrm{CTnI}$ in various studies. In this study, the cutoff value for cTnI was $0.03 \mu \mathrm{g} / \mathrm{l}$ which corresponded to the 99 th percentile cutoff with a CV $<10 \%$. This cutoff value was lower than those used in most of previous studies for diagnosis of AMI $(0.05-1.5 \mu \mathrm{g} / \mathrm{l})$ and thus enhanced its sensitivity.

Xinjiang is a multi-ethnic region. This study only included patients from Han, Uygur, Hui, Kazakh and Xibe, which occupy $98.2 \%$ of the population in Xinjiang. The Uygur and Han patients were dominated in this study as the Uygurs is the largest ethnic group (45\%) and the Han is the second (41\%). In this study, we found that there was no statistically significant difference in the diagnostic performance of the H-FABP immunotest among the Han and Uygur patients.

The prevalence rate of AMI case in the recruited cases not only depends on the inclusion and exclusion criteria, but also depends on recruiting site. In this study, the prevalence rate of AMI case recruited at the ED was $57 \%$ which was similar to the studies reported by Alhashemi et al. (64.1\%) [5] and Ecollan et al. (50.9\%) [6].

This study also demonstrated that there was no statistically significant difference in the diagnostic performance of the H-FABP immunotest among males and females. On the other hand, patients without both diabetes and hypertension gave the highest sensitivity but the lowest specificity. The low specificity could be explained by the small number of non-AMI cases in this group. Therefore, the diagnostic performance of H-FABP immunotest in patients with different chronic diseases should be further investigated. 


\subsection{Cardiac multi-marker strategy}

No single cardiac marker used alone is ideal. Although troponins are the gold standard cardiac markers, they still fail in two important aspects: the ability to detect early AMI and reinfarction. In view of the poor troponin sensitivity in the early detection of myocardial injury within the first $6 \mathrm{~h}$ after the onset of symptoms, a cardiac multimarker strategy is of particular value when the analytical sensitivity of the troponin detection method is unsatisfied. A panel consisting of $\mathrm{H}-\mathrm{FABP}$ and troponin is recommended rather than troponin in combination with myoglobin [27]. Patients presenting very early ( $<2$ to $3 \mathrm{~h}$ after symptom onset) may have elevations in H-FABP in the absence of $\mathrm{cTnI}$ increase. When $\mathrm{cTnI}$ is elevated in the absence of an H-FABP elevation, it is usually a delayed presentation. Most typically, discordant results are helpful to the clinician because they can identify a high-risk patient who may be missed if only one marker is tested.

The current study shows that a combination of H-FABP and cTnI tests gave the highest sensitivity and NPV while showed the specificity and PPV comparable to the cTnI test alone. This combination enhanced the sensitivity and NPV without sacrificing the specificity and PPV. The highest sensitivity and NPV of this combination play an important role in minimizing the number of false negative result and thus allowing safely exclusion of non-AMI patients at an early stage. It also gave the highest diagnostic accuracy and thus was the most effective diagnostic tool for diagnosis of AMI. Mion et al. [28] also demonstrated that the combination of cTnI and H-FABP gave the greatest diagnostic efficacy in AMI diagnosis in northern Italy. A rapid bedside immunotest allows H-FABP to be used in clinical settings, together with other clinical tools such as troponin test, to diagnose and treat cardiac patients as soon as possible so that mortality and morbidity can be decreased. This strategy may allow the complete detection of cardiac injury and may improve the diagnosis of AMI on the initial sample. Further investigation should be conducted to confirm the efficiency of this strategy.

\subsection{Limitations of the study}

This study was limited by the number of patients and a continuous measurement of H-FABP was omitted after confirmation as a negative case. Chan et al proved that the sensitivity and the negative predictive value of $\mathrm{H}-\mathrm{FABP}$ reached to $100 \%$ in $1 \mathrm{~h}$ after admission [16]. Whether the re-measurement of H-FABP negative samples after $1 \mathrm{~h}$ can improve the diagnostic accuracy should be further investigated.

\subsection{Impact on clinical practice}

As the therapeutic window for AMI is within the first $6 \mathrm{~h}$, and an earlier intervention has a better success rate, the availability of an early rapid test is important. In order to decrease the risk of falsely excluded patients with ongoing AMI, a combined measurement of two cardiac markers, an early one such as H-FABP and a later marker such as troponins may provide the optimum diagnostic performance.

In this study, a 1-step H-FABP immunotest based on a sandwich principle was evaluated. Apart from its high diagnostic accuracy the $\mathrm{H}$-FABP immunotest is very easy to be operated and thus favorable to be used in ambulance, emergency department and any emergency situation. Its simplicity in operation makes it a user-friendly test for application by chronic patients with high risk in AMI at home.

Recent studies about the application of the H-FABP immunotest for diagnosis of AMI were mainly reported in some developed countries like Europe and Japan [7-12]. Due to unfair distribution of medical resources across the world, the need of the H-FABP immunotest is always higher in the developing countries than the developed countries, especially for hospitals located at the countryside. The Xinjiang Uygur Autonomous Region is located in the North West corner of China. Its characteristics like low population density, poor transportation system, relatively poor economic and educational development, and lack of infrastructure improvements to promote hygiene reflects the key characteristics of the developing countries, and thus there is an urgent need to have a rapid system for early diagnosis of AMI.

This study can act as a model to demonstrate the utility of the H-FABP immunotest in the developing countries. In the second phase of this study, we will conduct a cost-effectiveness analysis on the utility of this test in the routine clinical practice and investigate whether this test can improve the clinical outcome and shorten the time of diagnosis compared to the original protocol.

The potential of this rapid and sensitive H-FABP immunotest in the detection of myocardial infarction is considerable. It may help physicians to diagnose AMI more accurately and earlier, leading to improved treatment that will reduce patient morbidity and mortality and prevent unnecessary hospital stays for non-AMI patients. This sophisticated and effective diagnostic tool could enable both physicians and patients to control diseases that now cause extensive disability and loss of life worldwide.

\section{Acknowledgement}

This study was supported by the grant from the Urumqi Science and Technology Bureau (Project code: Y07231004). We thank the staff of the Emergency Department of the First Affiliated Hospital of Xinjiang Medical University for their dedication and for diligently ensuring the highest possible level of data capture. We also thank Shenzhen Kang Sheng Bao Bio-Technology Co. Ltd (Shenzhen, China) for donation of the CardioDetect ${ }^{\circledR}$ rapid tests.

\section{References}

[1] Selker H, Zalenski R, Antman E, et al. An evaluation of technologies for identification of acute cardiac ischemia in the emergency department: a report from a National Heart Attack Alert Program Working Group. Ann Emerg Med 1997;29:13-87.

[2] Chan CPY, Wan TSM, Watkins KL, et al. Rapid analysis of fatty acid-binding proteins with immunosensors and immunotests for early monitoring of tissue injury. Biosens Bioelectron 2005;20(12):2566-80.

[3] Chan CP, Cheng WS, Glatz JFC, et al. Early diagnosis of acute myocardial infraction using immunosensors and immunotests. Anal Lett 2003;36:1987-2004.

[4] Chan CP, Sum KW, Cheung KY, et al. Development of a quantitative lateral-flow assay for rapid detection of fatty acid-binding protein. J Immunol Meth 2003;279: 91-100.

[5] Alhashemi JA. Diagnostic accuracy of a bedside qualitative immunochromatographic test for acute myocardial infarction. Am J Emerg Med 2006;24(2):149-55.

[6] Ecollan P, Collet JP, Boon G, et al. Pre-hospital detection of acute myocardial infarction with ultra-rapid human fatty acid-binding protein (H-FABP) immunoassay. Int J Cardiol 2007;119(3):349-54.

[7] Nakata T, Hashimoto A, Hase M, Tsuchihashi K, Shimamoto K. Human heart-type fatty acid-binding protein as an early diagnostic and prognostic marker in acute coronary syndrome. Cardiology 2003;99:96-104.

[8] Seino Y, Ogata K, Takano T, et al. Use of a whole blood rapid panel test for hearttype fatty acid-binding protein in patients with acute chest pain: comparison with rapid troponin T and myoglobin tests. Am J Med 2003;115:185-90.

[9] Valle HA, Riesgo LGC, Bel MS, Gonzalo FE, Sanchez MS, Oliva LL. Clinical assessment of heart-type fatty acid binding protein in early diagnosis of acute coronary syndrome. Eur J Emerg Med 2008;15(3):140-4.

[10] Figiel L, Kasprzak JD, Peruga J, et al. Heart-type fatty acid binding protein - a reliable marker of myocardial necrosis in a heterogeneous group of patients with acute coronary syndrome without persistent ST elevation. Kardiol Pol 2008;66(3): 260-1.

[11] Kim H. Diagnostic value of heart-type fatty acid-binding proteins (h-FABP) patients with hyperacute myocardial infarction. Ann Emerg Med 2008;52(4):S94

[12] PAfiAO/LU Hatice, OFLUO/LU Ebru, ,LHAN Mustafa N, et al. The role of heart-type fatty acid-binding protein (H-FABP) in acute myocardial infarction (AMI) compared to conventional cardiac biochemical markers. Turk J Med Sci 2007;37 (2):61-7.

[13] Alpert JS, Thygesen K, Antman E, Bassand JP. Myocardial infarction redefined - a consensus document of The Joint European Society of Cardiology/American College of Cardiology Committee for the redefinition of myocardial infarction. J Am Coll Cardiol 2000;36:959-69.

[14] Morrow DA, Cannon CP, Jesse RL, et al. National Academy of Clinical Biochemistry Laboratory Medicine Practice Guidelines: clinical characteristics and utilization of biochemical markers in acute coronary syndromes. Clin Chem 2007;53(4):552-74.

[15] Chan CPY, Lehmann M, Renneberg I, et al. A Novel Credit-Card Style Assay for Bedside Determination of Fatty Acid-Binding Protein. IVD Technology Magazine 2006;12(2):51. 
[16] Chan CPY, Sanderson JE, Glatz JFC, Cheng WS, Hempel A, Renneberg R. A superior early myocardial infarction marker - human heart-type fatty acid-binding protein. Z Kardiol 2004;93(5):388-97.

[17] Tong CY, Chan CPY, Cheung KY, Cautherley GWH, Glatz JFC, Renneberg R. A Pointof-Care Immunotest for Bedside Determination of Heart-type Fatty Acid-Binding Protein. Anal Lett 2010;43:735-44.

[18] Xie PV, Li YP, Chan CPY, Cheung KY, Cautherley GWH, Renneberg R. A one-step immunotest for rapid detection of heart-type fatty acid-binding protein in patients with acute coronary syndromes. J Immunoassay Immunochem 2010;31(1):24-32.

[19] Azzazy HM, Pelsers MM, Christenson RH. Unbound free fatty acids and heart-type fatty acid-binding protein: diagnostic assays and clinical applications. Clin Chem 2006:52(1):19-29.

[20] Ghani F, Wu AH, Graff L, et al. Role of heart-type fatty acid-binding protein in early detection of acute myocardial infarction. Clin Chem 2000;46(5):718-9.

[21] Ishii J, Wang JH, Naruse H, et al. Serum concentrations of myoglobin vs. human heart-type cytoplasmic fatty acid-binding protein in early detection of acute myocardial infarction. Clin Chem 1997;43:1372-8.

[22] Alhadi HA, Fox KAA. Do we need additional markers of myocyte necrosis: the potential value of heart fatty-acid-binding protein. Q J Med 2004;97:187-98.
[23] Yoshimoto K, Tanaka T, Somiya K, et al. Human heart-type cytoplasmic fatty acidbinding protein as an indicator of acute myocardial infarction. Heart Vessels 1995;10:304-5.

[24] Okamoto F, Sohmiya K, Ohkaru Y, et al. Human heart-type cytoplasmic fatty acidbinding protein (H-FABP) for the diagnosis of acute myocardial infarction. Clinical evaluation of H-FABP in comparison with myoglobin and creatine kinase isoenzyme MB. Clin Chem Lab Med 2000;38:231-8.

[25] Glatz JFC, Van der Voort D, Hermens WT. Fatty acid-binding protein as the earliest available plasma marker of acute myocardial injury. J Clin Lig Assay 2002;25: 167-77.

[26] Liao J, Chan CPY, Cheung YC, et al. Human heart-type fatty acid-binding protein for on-site diagnosis of early acute myocardial infarction. Int J Cardiol 2009;133(3): 420-3.

[27] McCann CJ, Glover BM, Menown IB, et al. Investigation of a multimarker approach to the initial assessment of patients with acute chest pain. Adv Ther 2009;26(5): 531-4.

[28] Mion MM, Novello E, Altinier S, Rocco S, Zaninotto M, Plebani M. Analytical and clinical performance of a fully automated cardiac multi-markers strategy based on protein biochip microarray technology. Clin Biochem 2007;40:1245-51. 